\title{
Outcome of pelvic arterial embolization for postpartum hemorrhage: A retrospective review of 117 cases
}

\author{
Ji Yoon Cheong ${ }^{1}$, Tae Wook Kong ${ }^{1}$, Joo Hyuk Son ${ }^{1}$, Je Hwan Won², Jeong In Yang ${ }^{1}$, Haeng Soo Kim \\ Departments of 'Obstetrics and Gynecology and ${ }^{2}$ Radiology, Ajou University School of Medicine, Suwon, Korea
}

\begin{abstract}
Objective
The aim of this study was to evaluate indications, efficacy, and complications associated with pelvic arterial embolization (PAE) for postpartum hemorrhage (PPH).
\end{abstract}

\section{Methods}

We retrospectively reviewed the medical records of 117 consecutive patients who underwent PAE for PPH between January 2006 and June 2013.

\section{Results}

In our single-center study, 117 women underwent PAE to control PPH refractory to conservative management including uterine massage, use of uterotonic agents, surgical repair of genital tract lacerations, and removal of retained placental tissues. Among 117 patients, 69 had a vaginal delivery and 48 had a Cesarean section. The major indication for embolization was uterine atony (54.7\%). Other causes were low genital tract lacerations (21.4\%) and abnormal placentation $(14.5 \%)$. The procedure showed a clinical success rate of $88.0 \%$ with 14 cases of PAE failure; there were 4 hemostatic hysterectomies and 10 re-embolizations. On univariate analysis, PAE failure was associated with overt disseminated intravascular coagulation $(P=0.009)$, transfusion of more than 10 red blood cell units (RBCUs, $P=0.002$ ) and embolization of both uterine and ovarian arteries $(P=0.003)$. Multivariate analysis showed that PAE failure was only associated with transfusions of more than 10 RBCUs (odds ratio, 8.011; 95\% confidence interval, 1.531-41.912; $P=0.014$ ) and embolization of both uterine and ovarian arteries (odds ratio, $20.472 ; 95 \%$ confidence interval, 2.715-154.365; $P=0.003$ ), which were not predictive factors, but rather, were the results of longer time for PAE. Three patients showed uterine necrosis and underwent hysterectomy.

\section{Conclusion}

PAE showed high success rates, mostly without procedure-related complications. Thus, it is a safe and effective adjunct or alternative to hemostatic hysterectomy, when primary management fails to control PPH.

Keywords: Hemostatic hysterectomy; Pelvic arterial embolization; Postpartum hemorrhage

\section{Introduction}

Postpartum hemorrhage (PPH) is a significant cause of maternal mortality worldwide, accounting for $25 \%$ to $30 \%$ of all maternal deaths [1]. PPH is a common entity that complicates as many as $18 \%$ of all deliveries, defined as an estimated blood loss of more than $500 \mathrm{~mL}$ by vaginal delivery (VD) and more than 1,000 $\mathrm{mL}$ by Cesarean section [1]. The most common causes of PPH include uterine atony, retained products of conception, placental abnormalities, lower genital tract
Received: 2013.5.3. Revised: 2013.7.10. Accepted: 2013.7.23.

Corresponding author: Haeng Soo Kim

Department of Obstetrics and Gynecology, Ajou University School of Medicine, 206 World cup-ro, Yeongtong-gu, Suwon 443-721, Korea Tel: +82-31-219-5248 Fax: +82-31-219-5245

E-mail: kimhs7@ajou.ac.kr

Articles published in Obstet Gynecol Sci are open-access, distributed under the terms of the Creative Commons Attribution Non-Commercial License (http://creativecommons. org/licenses/by-nc/3.0/) which permits unrestricted non-commercial use, distribution, and reproduction in any medium, provided the original work is properly cited.

Copyright (c) 2014 Korean Society of Obstetrics and Gynecology 


\title{
Obstetrics \& Gynecology Science
}

\author{
Vol. 57, No. 1, 2014
}

lacerations and coagulopathies. The major common complications of PPH are hypovolemic shock, disseminated intravascular coagulation (DIC), renal failure, hepatic failure, and adult respiratory distress syndrome [2]. Most patients can be managed conservatively by uterine massage, administration of uterotonics, surgical repair of genital tract lacerations, removal of retained placental tissues, vaginal packing or correction of coagulation disorders [2]. When PPH does not respond to conservative management, however, appropriate and timely intervention is critical for good clinical outcomes, because PPH is potentially life-threatening.

During the past 20 years, the frequency of emergency peripartum hysterectomy has decreased from $1 / 1,000$ to $1 / 2,000$ deliveries in developed countries [3]. This substantial drop might be due to marked improvements in medical resuscitation and an increased use of conservative treatments including pelvic artery ligation, uterine compression techniques, uterine balloon tamponade (UBT), and pelvic arterial embolization (PAE) [3]. However, the disadvantage of surgical treatments such as hypogastric artery ligation include low success rates $(<50 \%)$ due to abundant collateral blood supply to the uterus, the need for general anesthesia, and surgical complications including infection, bleeding, and ureteral injury $[4,5]$. Since selective uterine artery embolization showed success for PPH in 1979 by Brown et al. [6], it has emerged as a safe, effective and minimally invasive alternative to traditional surgical treatments such as hypogastric artery ligation or hysterectomy. Subsequently, several authors have reported the usefulness of this technique as a first-line treatment for PPH in those patients refractory to conservative treatment [7].

The goal of this study was to determine indications, efficacy, and complications of PAE in the management of PPH. In addition, we attempted to identify specific risk factors associated with an increased likelihood of failed PAE because identification of these factors may assist physicians in optimal management of PPH.

\section{Materials and methods}

This study was approved by our institutional review board. All consecutive patients who underwent PAE for PPH at our tertiary care center between January 2006 and June 2013 were included in this study. During the study period, a total of 129 patients underwent PAE owing to either primary or secondary
$\mathrm{PPH}$ despite conservative measures, of which 12 underwent hemostatic hysterectomy prior to PAE. Among 12 patients, 2 patients were transferred from other institutions after Cesarean hysterectomy, while 10 patients underwent Cesarean hysterectomy in our hospital. To evaluate the efficacy of PAE as primary management in the management of PPH, patients who had undergone Cesarean hysterectomy before PAE were excluded in this study. We reviewed the medical records of each patient to gather data regarding patients' and neonates' characteristics, etiologies of PPH, type of delivery, DIC scoring, blood transfusion, peri-interventional characteristics, periinterventional complications, and outcomes of the procedure. According to the International Society for Thrombosis and Haemostasis (ISTH) diagnostic scoring system for DIC, certain cut-off values were given to each global coagulation test so that the results could be represented by scores of 0,1 , or 2 . A cumulative score of five or more from prolonged prothrombin time, reduced platelets and fibrinogen, and elevated fibrin-related markers such as D-dimer and fibrin degradation product were considered to be overt DIC [8]. We calculated DIC scores providing objective measurement of DIC.

Initially, these patients were managed medically by correcting hypovolemia with intravenous fluids, transfusion of blood products, fresh frozen plasma or platelet concentrates in the presence of consumption coagulopathy as well as administration of uterotonics such as intravenous oxytocin, intramuscular methylergometrine, prostaglandin E2 analog sulprostone or prostaglandin E1 analog misoprostol. Uterine massage, repair of lower genital tract lacerations and uterine evacuation for retained placenta were performed if necessary. Once the obstetricians decided that primary measures were unlikely to control the hemorrhage, a qualified well-trained interventional radiologist performed PAE. During the procedure, the obstetricians continuously monitored vital signs and maintained hemodynamic stability.

Right femoral artery catheterization under local anesthesia was performed to get an initial pelvic aortogram for the selective uterine artery or anterior trunk of the hypogastric artery identification using Seldinger's technique. Extravasation of contrast medium is the hallmark of active hemorrhage. Uterine arteries were targeted first regardless of bleeding state because even if there is no extravasation of contrast material, uterine artery embolization is still effective in halting hemorrhage. In the presence of any remaining extravascular leakage of contrast agent, further selective occlusion of 


\section{Obstetrics \& Gynecology Science}

Ji Yoon Cheong, et al. Pelvic arterial embolization for postpartum hemorrhage

pelvic arterial branches was performed. We preferred to use pledges of absorbable gelatin sponge (Spongostan, Johnson \& Johnson, Gauteng, South Africa) that temporarily occludes vessels, resulting in uterine artery re-canalization to preserve the patient's future fertility. Microcoils (Hilal or Tornado, Cook, Bloomington, IN, USA), glue (Histoacryl, Braun, Sempach, Switzerland), or polyvinyl alcohol particles (Contour, Boston Scientific, Boston, MA, USA) were also used as primary embolic agents or additional embolic materials at the interventionist's discretion. At the end of the procedure, repeat angiography was routinely performed to confirm the satisfactory result of intact pelvic vasculature without residual extravasation. And then, the obstetricians checked cessation of vaginal bleeding on speculum inspection. Femoral arterial vascular sheaths remained in place for the following 24 hours, to provide rapid access in case of rebleeding that might cause hemodynamic instability. Clinical success was defined as the cessation of bleeding after PAE without the need for repeat PAE or additional surgical intervention during the hospital stay [9]. The definition of primary and secondary PPH was PPH occurring within the first 24 hours and from 24 hours to 6 weeks after delivery, respectively [10]. Hemodyanmic instability was defined as a systolic blood pressure lower than $90 \mathrm{mmHg}$ and heart rate greater than 120 beats/min despite adequate fluid resuscitation, or the need for continuous administration of an inotropic agent. The clinical features were compared between failed and successful PAE. In addition, we attempted to identify specific risk factors for the uterine necrosis.

Binary logistic regression analysis was performed. Differences were considered significant when $P<0.05$. The PAE failure factors with $P<0.05$ in univariate analysis were tested in multivariate analysis using binary logistic regression analysis. Statistical analysis was carried out using SPSS ver. 20.0 (IBM Co., Somers, NY, USA).

\section{Results}

During the study period, 117 women (mean age, 32 years) underwent PAE for PPH at our institution. Clinical data are summarized in Table 1. Sixty-nine patients (59.0\%) delivered via VD and forty-eight (41.0\%) via Cesarean delivery (CD). Fifty-six (47.9\%) women were primiparas and sixty-one (52.1\%) women were multiparas. The mean pregnancy term was 38 weeks and 12 women (11.1\%) had preterm deliveries. The suspected etiology was mostly uterine atony. However, other associated etiologies such as low genital tract laceration, placenta previa, and retained placenta were also present, often combined with uterine atony. Twenty-seven patients (23.1\%) delivered in our hospital and ninety women (76.9\%) were transferred from other institutions where interventional radiologic services were not available. There were 55 patients (47.0\%) who showed hemoglobin lower than $8 \mathrm{~g} / \mathrm{dL}$. Blood transfusion of more than 10 red blood cell units (RBCUs) was required in 43 women (36.8\%) accompanied by either DIC or hypovolemic shock. Thirty-three women (28.2\%) were overt DIC on the basis of laboratory tests performed before PAE. Univariate analysis showed that primiparous women (41 vs. 15 patients, $P=0.003$ ), primary PPH (62 vs. 39 patients, $P=0.032$ ) and transfer from other institutions (59 vs. 31 patients, $P=0.008$ ) were significantly associated with VD (Table 1). Among $69 \mathrm{VD}$ patients, 25 patients (36.2\%) showed extravasations from the internal iliac branches $(P<0.001)$. In the CD group, however, there were more preeclamptic women (6 vs. 1 patient, $P=0.013$ ) as well as abnormal placentation such as placenta previa and/or accreta (15 vs. 2 patients, $P<0.001)$. In the CD group, 3 patients showed arteriovenous malformation on angiography.

In 117 PPH patients, PAE was performed in 19 cases (16.2\%) for the secondary PPH (Table 1). Only in the secondary PPH group, 3 patients showed arteriovenous malformation on angiography. Also, there were 3 patients with retained placental fragments in the secondary PPH group. Compared to the secondary PPH, there were more primiparous (52 vs. 4 patients, $P=0.011$ ), more overt DIC (32 vs. 1 patient, $P=0.014$ ) and blood transfusion of $>10$ RBCUs (40 vs. 3 patients, $P=0.038$ ) in the primary PPH group (data not shown in Table). Although a majority of patients with primary PPH underwent PAE after $V D$, most of the patients following CD developed secondary PPH (62 of 98 primary PPH vs. 12 of 19 secondary PPH, $P=0.032$; data not shown in Table).

There were 20 patients who primarily underwent hysterectomy during or after the CD (Table 2). According to the univariate analysis between 117 patients of the PAE group and 20 of the hysterectomy group, there were also significant differences in age $(32 \pm 5.0$ vs. $35.0 \pm 4.0$ years, $P=0.006)$, primiparity (56 vs. 4 patients, $P=0.027$ ), abnormal placentation (17 vs. 15 patients, $P<0.001$ ) and blood transfusion $>10$ RBCU (43 vs. 19 patients, $P<0.001$ ).

The overall clinical success rate was $88.0 \%$ (103 of 117 


\title{
Obstetrics \& Gynecology Science
}

\author{
Vol. 57, No. 1, 2014
}

Table 1. Characteristics of the patients, neonates, PPH, and periembolization data according to the mode of delivery

\begin{tabular}{|c|c|c|c|}
\hline \multirow{2}{*}{ Characteristics } & \multicolumn{2}{|c|}{ Type of delivery } & \multirow{2}{*}{$P$-value } \\
\hline & Vaginal $(n=69)$ & Cesarean $(n=48)$ & \\
\hline PAE failure & $9(13.0)$ & $5(10.4)$ & 0.667 \\
\hline \multicolumn{4}{|l|}{ Maternal characteristics } \\
\hline Age (yr) & $32.0 \pm 5.0$ & $33.0 \pm 5.0$ & 0.297 \\
\hline Primiparity & $41(59.4)$ & $15(31.3)$ & 0.003 \\
\hline Twin pregnancy & $0(0.0)$ & $3(6.3)$ & 0.999 \\
\hline Preeclampsia & $1(1.4)$ & $6(12.5)$ & 0.038 \\
\hline \multicolumn{4}{|l|}{ Neonatal characteristics } \\
\hline Gestational age (wk) & & & 0.175 \\
\hline$<34$ & $0(0.0)$ & $1(2.1)$ & \\
\hline 34-36 wk 6 day & $4(5.8)$ & $8(16.7)$ & \\
\hline$\geq 37$ & $65(94.2)$ & $39(81.3)$ & \\
\hline Birth weight $\geq 4,000 \mathrm{~g}$ & $5(7.2)$ & $3(6.3)$ & 0.834 \\
\hline \multicolumn{4}{|l|}{ PPH characteristics } \\
\hline Type of PPH & & & 0.032 \\
\hline Primary & $62(89.9)$ & $36(75.0)$ & \\
\hline Secondary & $7(10.1)$ & $12(25.0)$ & \\
\hline \multicolumn{4}{|l|}{ Cause of PPH } \\
\hline Uterine atony & $39(56.5)$ & $25(52.1)$ & 0.635 \\
\hline Abnormal placentation ${ }^{a)}$ & $2(2.9)$ & $15(31.3)$ & $<0.001$ \\
\hline Low genital tract trauma & $25(36.2)$ & $0(0.0)$ & 0.998 \\
\hline Retained placental fragments & $2(2.9)$ & $1(2.1)$ & 0.785 \\
\hline Others ${ }^{\mathrm{b})}$ & $1(1.4)$ & $7(14.6)$ & - \\
\hline Overt DIC & $19(27.5)$ & $14(29.8)$ & 0.792 \\
\hline Hospital-to-hospital transfer & $59(85.5)$ & $31(64.6)$ & 0.010 \\
\hline \multicolumn{4}{|l|}{ Peri-interventional characteristics } \\
\hline Hemodynamic instability & $32(46.4)$ & $21(43.8)$ & 0.779 \\
\hline Initial hemoglobin $<8 \mathrm{~g} / \mathrm{dL}$ & $35(50.7)$ & $20(41.7)$ & 0.335 \\
\hline More than 10 RBCU transfused & $21(30.4)$ & $22(45.8)$ & 0.091 \\
\hline \multicolumn{4}{|l|}{ Extravasation site } \\
\hline No extravasationc) & $8(11.6)$ & $8(16.7)$ & 0.651 \\
\hline Only uterine arteries & $33(47.8)$ & $22(45.8)$ & 0.936 \\
\hline Arteries related to lower genital tract trauma ${ }^{\mathrm{d})}$ & $25(36.2)$ & $0(0.0)$ & 0.998 \\
\hline Arteries related to (esarean delivery ${ }^{\mathrm{e})}$ & $0(0.0)$ & $13(27.1)$ & 0.999 \\
\hline Pseudoaneurysm & $3(4.3)$ & $2(4.2)$ & 0.987 \\
\hline Arteriovenous malformation & $0(0.0)$ & $3(6.3)$ & 0.999 \\
\hline No. of PAE & & & 0.459 \\
\hline 1 & $62(89.9)$ & $45(93.8)$ & \\
\hline$\geq 2$ & $7(10.1)$ & $3(6.3)$ & \\
\hline Hemostatic hysterectomy & $2(2.9)$ & $2(4.2)$ & 0.710 \\
\hline
\end{tabular}

Binary logistic regression analysis was performed.

Data are presented as number (\%) or mean \pm standard deviation.

PPH, postpartum hemorrhage; PAE, pelvic arterial embolization; DIC, disseminated intravascular coagulation; RBCU, red blood cell unit.

${ }^{a)}$ Abnormal placentation includes placenta previa and/or creta (accreta, increta or percreta); ${ }^{\text {b) } O t h e r s ~ i n c l u d e ~ p s e u d o a n e u r y s m ~ o f ~ t h e ~}$ vaginal (1 patient) and superior vesical arteries (1 patient) and the injury of inferior epigastric (5 patients) and superior vesical arteries (1

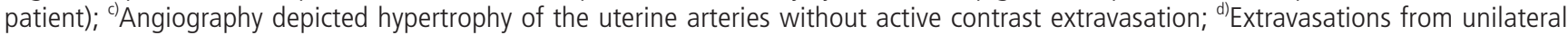

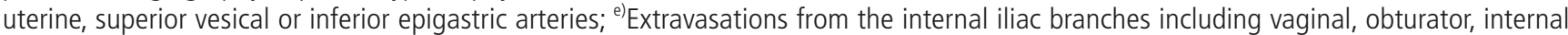
pudendal, inferior gluteal or lateral sacral arteries except uterine arteries. 


\section{Obstetrics \& Gynecology Science}

Ji Yoon Cheong, et al. Pelvic arterial embolization for postpartum hemorrhage

Table 2. Comparison of clinical characteristics between PAE group and hysterectomy group

\begin{tabular}{|c|c|c|c|}
\hline Characteristic & PAE group $(n=117)^{a)}$ & Hysterectomy group $(n=20)^{b}$ & $P$-value \\
\hline \multicolumn{4}{|l|}{ Maternal characteristics } \\
\hline Age (yr) & $32.0 \pm 5.0$ & $35.0 \pm 4.0$ & 0.006 \\
\hline Primiparity & $56(47.9)$ & $4(20.0)$ & 0.027 \\
\hline Twin pregnancy & $3(2.6)$ & $0(0.0)$ & 0.999 \\
\hline Preeclampsia & $7(6.0)$ & $3(15.0)$ & 0.167 \\
\hline Previous Cesarean delivery & $24(20.5)$ & $14(70.0)$ & $<0.001$ \\
\hline \multicolumn{4}{|l|}{ Neonatal characteristics } \\
\hline Gestational age (wk) & & & 0.082 \\
\hline$<34$ & $1(0.9)$ & $1(5.0)$ & \\
\hline 34-36 wk 6 day & $12(10.3)$ & $5(25.0)$ & \\
\hline$\geq 37$ & $104(88.9)$ & $14(70.0)$ & \\
\hline Birth weight $\geq 4,000 \mathrm{~g}$ & $8(6.8)$ & $0(0.0)$ & 0.999 \\
\hline Delivery mode & & & $<0.001$ \\
\hline Vaginal & $69(59.0)$ & $3(15.0)$ & \\
\hline Cesarean & $48(41.0)$ & $17(85.0)$ & \\
\hline \multicolumn{4}{|l|}{ PPH characteristics } \\
\hline \multicolumn{4}{|l|}{ Cause of PPH } \\
\hline Uterine atony & $64(54.7)$ & $2(10.0)$ & $<0.001$ \\
\hline Abnormal placentation & $17(14.5)$ & $15(75.0)$ & $<0.001$ \\
\hline Low genital tract trauma & $25(21.4)$ & $3(15.0)$ & 0.517 \\
\hline Retained placental fragments & $3(2.6)$ & $0(0.0)$ & 0.999 \\
\hline Others ${ }^{c}$ & $8(6.8)$ & $0(0.0)$ & - \\
\hline Overt DIC & $33(28.4)$ & $3(15.0)$ & 0.131 \\
\hline Hospital-to-hospital transfer & $90(76.9)$ & $5(25.0)$ & $<0.001$ \\
\hline \multicolumn{4}{|l|}{ Peri-interventional characteristics } \\
\hline Hemodynamic instability & $53(45.3)$ & $4(80.0)^{a)}$ & 0.165 \\
\hline Initial hemoglobin $<8 \mathrm{~g} / \mathrm{dL}$ & $55(47.0)$ & $2(40.0)$ & 0.573 \\
\hline More than 10 RBCU transfused & $43(36.8)$ & $19(95.0)$ & $<0.001$ \\
\hline
\end{tabular}

Binary logistic regression analysis was performed.

Data are presented as number (\%) or mean \pm standard deviation.

PAE, pelvic arterial embolization; PPH, postpartum hemorrhage; DIC, disseminated intravascular coagulation; RBCU, red blood cell unit.

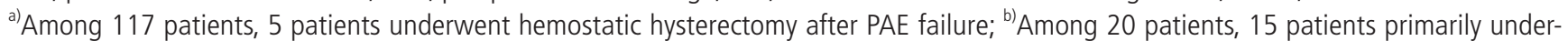
went Cesarean hysterectomy whereas hemostatic hysterectomy was primarily performed in 5 patients after vaginal ( 3 patients) or Cesarean ( 2 patients) delivery; ${ }^{\text {c)}}$ Others include pseudoaneurysm of the vaginal ( 1 patient) and superior vesical arteries ( 1 patient) and the injury of inferior epigastric (5 patients) and superior vesical arteries (1 patient).

patients). The success group showed good clinical outcomes, but 3 cases of uterine necrosis occurred. Fourteen patients were clinical failures that required hemostatic hysterectomies (4 cases) and repeat PAE (10 cases). On univariate analysis, failure of PAE was associated with overt DIC (25 vs. 8 patients, $P=0.009$ ), more than 10 RBCUs transfused (32 vs.
11 patients, $P=0.002$ ) and embolization of both uterine and ovarian arteries (4 vs. 4 patients, $P=0.003$ ) (Table 3 ). Multivariate analysis showed that PAE failure was only associated with more than 10 RBCUs transfused (odds ratio, $8.011 ; 95 \%$ confidence interval, $1.531-41.912 ; P=0.014$ ) and embolization of both uterine and ovarian arteries (odds 


\title{
Obstetrics \& Gynecology Science
}

\author{
Vol. 57, No. 1, 2014
}

Table 3. Comparison of clinical characteristics between successful and failed PAE

\begin{tabular}{|c|c|c|c|}
\hline Characteristic & PAE success $(n=103)$ & PAE failure $(n=14)$ & $P$-value \\
\hline \multicolumn{4}{|l|}{ Maternal characteristics } \\
\hline Age (yr) & $32.0 \pm 5.0$ & $34.0 \pm 4.0$ & 0.166 \\
\hline Primiparity & 51 (49.5) & $5(35.7)$ & 0.337 \\
\hline Preeclampsia & $6(5.8)$ & $1(7.1)$ & 0.846 \\
\hline Twin pregnancy & $2(1.9)$ & $1(7.1)$ & 0.281 \\
\hline Previous Cesarean delivery & $22(21.4)$ & $2(14.3)$ & 0.542 \\
\hline \multicolumn{4}{|l|}{ Neonatal characteristics } \\
\hline Gestational age (wk) & & & 0.917 \\
\hline$<34$ & $1(1.0)$ & $0(0.0)$ & \\
\hline 34-36 wk 6 day & $11(10.7)$ & $1(7.1)$ & \\
\hline$\geq 37$ & $91(88.3)$ & $13(92.9)$ & \\
\hline Birth weight $\geq 4,000 \mathrm{~g}$ & $7(6.8)$ & $1(7.1)$ & 0.962 \\
\hline Mode of delivery & & & 0.667 \\
\hline Vaginal & $60(58.3)$ & $9(64.3)$ & \\
\hline Cesarean & $43(41.7)$ & $5(35.7)$ & \\
\hline \multicolumn{4}{|l|}{ PPH characteristics } \\
\hline Type of PPH & & & 0.344 \\
\hline Primary & $85(82.5)$ & $13(92.9)$ & \\
\hline Secondary & $18(17.5)$ & $1(7.1)$ & \\
\hline \multicolumn{4}{|l|}{ Cause of PPH } \\
\hline Uterine atony & $57(55.3)$ & $7(50.0)$ & 0.707 \\
\hline Abnormal placentation & $14(13.6)$ & $3(21.4)$ & 0.440 \\
\hline Low genital tract trauma & $22(21.4)$ & $3(21.4)$ & 0.995 \\
\hline Retained placental fragments & $2(1.9)$ & $1(7.1)$ & 0.281 \\
\hline Others ${ }^{a)}$ & $8(7.8)$ & $0(0.0)$ & - \\
\hline Overt DIC & $25(24.3)$ & $8(61.5)$ & 0.009 \\
\hline Hospital-to-hospital transfer & $81(78.6)$ & $9(64.3)$ & 0.239 \\
\hline \multicolumn{4}{|l|}{ Peri-interventional characteristics } \\
\hline Hemodynamic instability & $44(42.7)$ & $9(64.3)$ & 0.137 \\
\hline Initial hemoglobin $<8 \mathrm{~g} / \mathrm{dL}$ & $48(46.6)$ & $7(50.0)$ & 0.811 \\
\hline More than $10 \mathrm{RBCU}$ transfused & $32(31.1)$ & $11(78.6)$ & 0.002 \\
\hline Nature of embolizing agent & & & 0.062 \\
\hline Temporary & $71(68.9)$ & $6(42.9)$ & \\
\hline Permanent & $32(31.1)$ & $8(57.1)$ & \\
\hline \multicolumn{4}{|l|}{ Nature of arteries embolized } \\
\hline Cervicovaginal branch & $1(1.0)$ & $0(0.0)$ & $>0.999$ \\
\hline Uterine artery & $78(75.7)$ & $8(57.1)$ & 0.147 \\
\hline Internal iliac artery and/or branches & $13(12.6)$ & $2(14.3)$ & 0.861 \\
\hline Uterine and ovarian arteries & $4(3.9)$ & $4(28.6)$ & 0.003 \\
\hline Others ${ }^{b)}$ & $7(6.8)$ & $0(0.0)$ & 0.999 \\
\hline No. of PAE & & & 0.998 \\
\hline 1 & $103(100.0)$ & $4(28.6)$ & \\
\hline$\geq 2$ & $0(0.0)$ & $10(71.4)$ & \\
\hline
\end{tabular}

Binary logistic regression analysis was performed.

Data are presented as number (\%) or mean \pm standard deviation.

PAE, pelvic arterial embolization; PPH, postpartum hemorrhage; DIC, disseminated intravascular coagulation; RBCU, red blood cell unit. ${ }^{\text {a) }}$ Others include pseudoaneurysm of the vaginal (1 patient) and superior vesical arteries (1 patient) and the injury of inferior epigastric (5 patients) and superior vesical arteries (1 patient); ${ }^{\text {b) }}$ Others include pseudoaneurysm of the superior vesical artery (1 patient) and inferior epigastric (5 patients) and superior vesical arteries (1 patient). 


\section{Obstetrics \& Gynecology Science}

Ji Yoon Cheong, et al. Pelvic arterial embolization for postpartum hemorrhage

Table 4. Multivariate analysis of failed pelvic arterial embolization after postpartum hemorrhage

\begin{tabular}{|lccc|}
\hline Variables & OR & 95\% Cl & \multicolumn{1}{c|}{$\boldsymbol{P}$-value } \\
\hline Overt DIC & 3.364 & $0.838-13.503$ & 0.081 \\
More than 10 RBCU transfused & 8.011 & $1.531-41.912$ & 0.014 \\
Uterine and ovarian arteries & 20.472 & $2.715-154.365$ & 0.003 \\
\hline
\end{tabular}

Binary logistic regression analysis was performed.

$\mathrm{OR}$, odds ratio; $\mathrm{Cl}$, confidence interval; DIC, disseminated intravascular coagulation; RBCU, red blood cell unit.

Table 5. Peri-interventional complications

\begin{tabular}{|lc|}
\hline Complications & $19(14.5)$ \\
\hline PPH-related complications & $12(10.3)$ \\
Acute renal failure & $5(4.3)$ \\
Hepatic failure & $1(0.9)$ \\
Pulmonary edema & $3(2.6)$ \\
Postpartum cardiomyopathy & $3(2.6)$ \\
PAE-related complications & $7(6.0)$ \\
Uterine necrosis requiring hysterectomy & $3(2.6)$ \\
Buttock necrosis requiring surgical debridement & $0(0.0)$ \\
Fever higher than $38.5^{\circ} \mathrm{C}$ without a focus of infection & $2(1.7)$ \\
Puncture site hematoma & $2(1.7)$ \\
\hline
\end{tabular}

Values are presented as number (\%).

$\mathrm{PPH}$, postpartum hemorrhage; PAE, pelvic arterial embolization.

ratio, 20.472; 95\% confidence interval, 2.715-154.365; $P=0.003$ ) (Table 4).

Regardless of clinical success in hemostasis by PAE, some patients suffered from procedure-related complications. The peri-interventional complications of PAE that we experienced are listed in Table 5. In the case of uterine necrosis, hysterectomy was inevitably done, due to the concern of possible sepsis even without any sign of further bleeding. Three patients developed uterine necrosis after PAE. On univariate analysis, uterine necrosis was significantly associated with abnormal placentation ( 15 vs. 2 patients, $P=0.040$ ) and the number of PAE (1 vs. 3 times, $P=0.012$ ) (data not shown in Table). Among 3 patients with uterine necrosis, there was abnormal placentation in 2 patients and one patient who underwent PAE 3 times showed uterine necrosis.

\section{Discussion}

PPH is one of the major causes of maternal morbidity and mortality worldwide. Although uterine atony is the major cause of primary PPH, there are some other etiologies such as the lower genital tract laceration, retained placenta or coagulopathy [11]. Uterine atony, the major cause of PPH in the present study, did not respond to uterotonic agents and uterine packing, appearing in conjunction with dilutional coagulopathy due to excessive hemorrhage. If PPH cannot be successfully controlled by uterine massage and uterotonic agents, there are several other treatment options. Traditionally, surgical uterine-sparing techniques including balloon tamponade (i.e., Bakri balloon use), compression sutures, and uterine or internal arterial ligation were considered as management options. However, internal iliac artery ligation has shown a more than $50 \%$ failure rate because of a rich collateral circulation in the pelvis [12]. In the past, loss of fertility was a concern after hemostatic hysterectomy following failed uterine-sparing techniques. Recently, with advances in radiologic intervention, the chances of effective bleeding control have prominently increased due to PAE. Also, uterine-sparing techniques are not significantly effective over $\mathrm{PAE}$, as described in a recent metaanalysis of conservative management for PPH [13]. Thus, PAE is widely accepted as the primary treatment for medically unresponsive PPH. There have been several studies in the literature on the safety and efficacy of PAE for the treatment 


\title{
Obstetrics \& Gynecology Science
}

\author{
Vol. 57, No. 1, 2014
}

of PPH [14-23]. The success rate of the procedure performed by experienced interventional radiologists has been reported to be more than $90 \%[24,25]$. Our success rate $(88.0 \%)$ was similar to reported success rates, which range from $82 \%$ and $100 \%$.

The blood supply to the upper vagina is from a rich anastomotic network of vessels, arising mainly from branches of the anterior trunk of the internal iliac artery (vaginal, uterine, middle rectal arteries) and the internal pudendal artery, which is the most inferior branch of the posterior trunk of the internal iliac artery. Among 69 VD patients, 25 patients (36.2\%) showed extravasations from the internal iliac branches including the vaginal, obturator, internal pudendal, inferior gluteal and lateral sacral arteries except uterine arteries. In the case of VD, therefore, superselective catheterization and arteriogram of internal iliac branches was required to assess the extent of extravasations. In addition, there was an injury of the inferior epigastric artery in 5 out of 48 CD patients who were all transferred from other institutions after Cesarean section. They presented with severe abdominal pain with tenderness to the touch. Also, generalized oozing thorough the wound was noted. But, they were hemodynamically stable without profuse vaginal bleeding. Although selective uterine arteriography demonstrated tortuous hypertrophied uterine arteries, there were no definite extravasations from the uterine arteries. Following catheterization of the uterine artery, selective external iliac artery injection demonstrated a contrast blush in the pelvis, which was subsequently embolized using gelatin sponge. All patients developed jaundice during the recovery period. Typical arterial injury sites in PPH involve branches of the internal iliac artery, but the inferior epigastric artery is an atypical source of PPH. Therefore, the patients who have severe lower abdominal pain after Cesarean section require angiography to evaluate the inferior epigastric artery, a branch of the external iliac artery, as well as the extravasations from the internal iliac branches.

In $117 \mathrm{PPH}$ patients, PAE was performed in 19 cases (16.2\%) for secondary PPH. Compared to the secondary PPH, there were more primiparous women, more overt DIC and blood transfusion of $>10$ RBCUs in the primary PPH group. Among 19 secondary PPH patients, 3 patients showed arteriovenous malformation on angiography, combined with uterine atony. Retained placental fragments appeared in 3 secondary PPH patients, while none were found in primary PPH. Only one patient showed overt DIC in the secondary PPH group. In ad- dition, there was one case of PAE failure in this group. Thus, PAE of both uterine arteries and/or internal iliac branches was enough to stop hemorrhage for the secondary PPH.

There were 20 patients who primarily underwent hysterectomy during or after the CD (Table 2). In particular, 15 patients had a CD with placenta previa and accreta in our hospital, whereas 2 patients, who had not undergone Cesarean wound closure at another institution, immediately underwent hemostatic hysterectomy in our hospital. Only 3 patients were transferred from other facilities for lower genital tract laceration and/or paravaginal hematoma after VD and immediately managed by hemostatic hysterectomy due to overt DIC, hemodynamic instability and drowsy mental status on arrival. On univariate analysis, age, multiparity and placenta previa with accreta and blood transfusion of $>10$ RBCUs were significantly associated with primary hysterectomy. Thus, most of the high-risk patients who had our follow-up for placenta previa totalis with placenta accreta underwent Cesarean hysterectomy. These patients were more multiparous and more frequently older than 35 years of age in comparison to the patients in the PAE group.

There have been some studies describing predictive factors of failed PAE for intractable PPH. Sentilhes et al. [26] reported that failure of PAE was associated with a higher rate of estimated blood loss (more than 1,500 mL) and transfusion of more than 5 RBCUs. These two items, however, were used to assess the final and not initial clinical status of the patient. Moreover, visual assessment underestimates the amount of blood loss in approximately $45 \%$ of cases [16]. Therefore, these two predictors were significantly associated with failed PAE and could not be considered true or useful predictive factors. In another study, Zwart et al. [19] assessed the risk factors of peripartum hysterectomy and arterial embolization for major obstetric hemorrhage. After the failure of PAE among 114 patients, 17 women underwent hysterectomy. Univariate analysis indicated that CD and multiple pregnancy were the most important risk factors. We assumed that the result was affected by the increased incidence of Cesarean section. However, in our study, previous CD was not associated with failed PAE. Recently, Poujade et al. [27] suggested that several factors, including placenta accreta, biological factors (hemoglobin level, PT, and fibrinogen level) and transfusion factors (red blood transfusion, number of packed RBCUs transfused and fresh frozen plasma transfusion), were associated with PAE failure. However, 


\section{Obstetrics \& Gynecology Science}

Ji Yoon Cheong, et al. Pelvic arterial embolization for postpartum hemorrhage

there were too many predictive factors and the authors also could not perform multivariate analysis.

The cornerstone of the treatment of PPH is to stop hemorrhage concurrently with correction of DIC. As in our study, the majority of patients were transferred to a tertiary center. Emergency treatment, therefore, may be delayed, giving an amount of time for DIC to occur, which worsens the prognosis. Thus, this research evaluated the significance of DIC as a risk factor for failed PAE, using the ISTH DIC scoring system. We had 25 cases $(24.3 \%)$ of overt DIC in the successful PAE group and 8 (61.5\%) in the failed PAE group, demonstrating the value of overt DIC as a predictive factor for failed PAE. Recently, Kim et al. [23] also found that DIC was the only independent predictor of PAE failure. Hence, DIC scores might serve as a treatment guideline and a possible predictor for PAE failure, thus providing guidance for proper management. On multivariate analysis, however, overt DIC failed to show significant correlations with PAE failure. PAE failure was only associated with transfusion of more than 10 RBCUs and simultaneous embolization of both uterine and ovarian arteries, which were not predictive factors, but rather, the results of longer time for PAE. If the time required for PAE is longer, the patient receives more RBCU transfusion. In the case of typical ovarian blush and abundant collateral perfusion to the markedly enlarged uterus, additional PAE was required. In this study, therefore, there were no significant predictors for PAE failure.

In the second trial of embolization performed in 6 patients, recanalization of the previously embolized vessels was evident despite the short time intervals ( $<6$ hours). Re-embolization stopped hemorrhage using glue in 3, microcoil in 1 and gelatin sponge in 1 patient, but one patient underwent hemostatic hysterectomy owing to the hemodynamic instability. In particular, one patient who underwent re-embolization using microcoil in December 2008 had a reported pregnancy in December 2012. Our findings suggest that recanalization may be one of the causes of recurrent bleeding. In 5 recanalized cases, however, re-embolization successfully stopped $\mathrm{PPH}$. Therefore, we assume that it is appropriate to consider re-embolization prior to hemostatic hysterectomy if the patient is hemodynamically stable. There were 5 patients who underwent embolization of both uterine arteries without confirmation of collateral circulation. Subsequent angiography revealed ovarian collaterals. In addition, selective unilateral uterine artery was blocked using gelatin sponge in 3 patients.
Re-embolization stopped hemorrhage in 2 patients, whereas hemostatic hysterectomy was performed in 1 patient. Thus, we recommend that both uterine arteries should be prophylactically embolized even without specific extravasation sites. Subsequently, angiographic study for other collaterals including ovarian arteries should be performed to avoid additional embolization or hysterectomy.

Immediate complications after PAE are frequently reported: pain, transient fever, mild numbness of the buttock, and hematoma formation at the site of the common femoral artery puncture $[15,28]$. In addition, possibly delayed complications include pelvic infection, transient ovarian failure, vaginal fistula, uterine and bladder wall necrosis, and neurologic damage [22]. Lower extremity ischemic complications secondary to reflux of gelfoam particles to the external iliac artery and distally have also been reported and have required interventions, such as embolectomy, fasciotomy, debridement, and amputation [29]. With adequate expertise and skill, however, the postprocedural complication rate is low and can be minimized to less than $1.6 \%$ [30]. Also, we did not experience any major complications requiring surgical interventions. However, three patients had intractable uterine necrosis, requiring hysterectomy. As described in the results, uterine necrosis was associated with abnormal placentation, such as placenta previa with accreta, and the number of PAE performed $(\geq 3)$. In the first case, intraoperative hemostatic suture was performed during Cesarean section for placenta previa with accreta followed by 3-fold performance of PAE covering both uterine and ovarian arteries. In another case of uterine necrosis, the patient underwent a Cesarean section for placenta previa with accreta where intraoperative hemostatic suture and subsequent PAE were performed. However, the patient was readmitted to the hospital 15 days later with fever and abdominal pain. Computed tomography (CT) showed $15-\mathrm{cm}$ sized pyometra and myometrial thinning, which led to the performance of hysterectomy. The last case of the uterine necrosis developed after Cesarean section at other institution. Immediate PAE on arrival stopped hemorrhage, but left a persistent $15-\mathrm{cm}$ sized hematometra in the uterine cavity in CT. Subsequently, the patient developed pyometra with myometrial thinning from persistently infected hematometra in the uterine cavity that reduced blood supply to the uterus leading to the uterine necrosis. We assumed that hematometra gave compressive effects to the uterus like UBT or otherwise suppressed blood supply to the uterus developing uterine necrosis. Therefore, it 


\title{
Obstetrics \& Gynecology Science
}

\author{
Vol. 57, No. 1, 2014
}

is important to detect any sign of uterine infection and blood flow reduction by follow-up CT or sonography in PPH treated by PAE. Thus, it should be emphasized that maintenance of adequate blood flow to the uterus is as important as cessation of bleeding in PPH management.

In regard to PPH-related complication, acute renal failure $(n=5)$ was successfully treated with fluid replacement and transfusion. Although the etiology was not identified, one patient died of hepatic failure two months later despite liver transplantation. In addition, there were 3 patients with cardiomyopathy, all of whom had PPH successfully controlled by PAE. However, they showed overt DIC and transfusion of more than 30 RBCUs in a relatively short period. In particular, inotropic agent was used in two patients. An echocardiogram showed left ventricular ejection fraction (EF) of $30 \%$ to $40 \%$ in all patients. After administrating angiotensin-converting enzyme inhibitors and diuretics for several weeks in 2 patients, EF was normalized to $60 \%$ to $70 \%$ over a 1 to 2 month follow-up period. A third patient showed echocardiographic left ventricular EF that spontaneously recovered in a week without any medication.

This study had some limitations due to the relatively small number of patients, and retrospective nature of the study. In particular, there was a concern related to the consistency of pre-embolization medical management of PPH and clinical status because a significant number of patients were referred from other facilities. This study also lacked statistical power because the sample size of the outcome of interest was low. This lack of statistical power did not permit us to identify true predictive factors of failed PAE. In addition, although fertility preservation is an important advantage of embolization over surgery, we did not assess the long-term effects of PAE on menses, fertility and future pregnancy evolution, particularly when permanent embolic material was used. Further research is required to assess reappearance of normal menstruation and future fertility outcome.

In conclusion, the preservation of the uterus conserves future fertility, which is a distinct advantage of PAE. PAE showed a high success rate, mostly without procedure-related complications. Thus, it is a safe and effective adjunct or alternative to hemostatic hysterectomy, when primary therapeutic management fails to control intractable PPH.

\section{Conflict of interest}

No potential conflict of interest relevant to this article was reported.

\section{References}

1. Devine PC. Obstetric hemorrhage. Semin Perinatol 2009;33:76-81.

2. Bonnar J. Massive obstetric haemorrhage. Baillieres Best Pract Res Clin Obstet Gynaecol 2000;14:1-18.

3. Flood KM, Said S, Geary M, Robson M, Fitzpatrick C, Malone FD. Changing trends in peripartum hysterectomy over the last 4 decades. Am J Obstet Gynecol 2009;200:632.e1-6.

4. Clark SL, Phelan JP, Yeh SY, Bruce SR, Paul RH. Hypogastric artery ligation for obstetric hemorrhage. Obstet Gynecol 1985;66:353-6.

5. Vedantham S, Goodwin SC, McLucas B, Mohr G. Uterine artery embolization: an underused method of controlling pelvic hemorrhage. Am J Obstet Gynecol 1997;176:93848.

6. Brown BJ, Heaston DK, Poulson AM, Gabert HA, Mineau $D E$, Miller FJ Jr. Uncontrollable postpartum bleeding: a new approach to hemostasis through angiographic arterial embolization. Obstet Gynecol 1979;54:361-5.

7. Gonsalves $\mathrm{M}$, Belli $A$. The role of interventional radiology in obstetric hemorrhage. Cardiovasc Intervent Radiol 2010;33:887-95.

8. Levi M, Toh CH, Thachil J, Watson HG. Guidelines for the diagnosis and management of disseminated intravascular coagulation. British Committee for Standards in Haematology. Br J Haematol 2009;145:24-33.

9. Kirby JM, Kachura JR, Rajan DK, Sniderman KW, Simons ME, Windrim RC, et al. Arterial embolization for primary postpartum hemorrhage. J Vasc Interv Radiol 2009;20:1036-45.

10. Cunningham FG, Bloom SL, Gilstrap LC, Hauth JC, Rouse DJ, Spong CY. Williams obstetrics. 23rd ed. New York: McGraw-Hill Medical; 2010.

11. Varner M. Postpartum hemorrhage. Crit Care Clin 1991;7:883-97.

12. Evans S, McShane P. The efficacy of internal iliac artery ligation in obstetric hemorrhage. Surg Gynecol Obstet 


\section{Obstetrics \& Gynecology Science}

Ji Yoon Cheong, et al. Pelvic arterial embolization for postpartum hemorrhage

1985;160:250-3.

13. Doumouchtsis SK, Papageorghiou AT, Arulkumaran S. Systematic review of conservative management of postpartum hemorrhage: what to do when medical treatment fails. Obstet Gynecol Surv 2007;62:540-7.

14. Lee HY, Shin JH, Kim J, Yoon HK, Ko GY, Won HS, et al. Primary postpartum hemorrhage: outcome of pelvic arterial embolization in 251 patients at a single institution. Radiology 2012;264:903-9.

15. Tsang ML, Wong WC, Kun KY, Tai CM, Ng TK, Lau KY, et al. Arterial embolisation in intractable primary postpartum haemorrhage: case series. Hong Kong Med J 2004;10:301-6.

16. Tourne $G$, Collet F, Seffert P, Veyret $C$. Place of embolization of the uterine arteries in the management of postpartum haemorrhage: a study of 12 cases. Eur J Obstet Gynecol Reprod Biol 2003;110:29-34.

17. Agarwal N, Deinde O, Willmott F, Bojahr H, MacCallum $P$, Renfrew I, et al. A case series of interventional radiology in postpartum haemorrhage. J Obstet Gynaecol 2011;31:499-502.

18. Salomon LJ, deTayrac R, Castaigne-Meary V, Audibert F, Musset D, Ciorascu R, et al. Fertility and pregnancy outcome following pelvic arterial embolization for severe post-partum haemorrhage: a cohort study. Hum Reprod 2003; 18:849-52.

19. Zwart JJ, Dijk PD, van Roosmalen J. Peripartum hysterectomy and arterial embolization for major obstetric hemorrhage: a 2-year nationwide cohort study in the Netherlands. Am J Obstet Gynecol 2010;202:150.e1-7.

20. Ornan D, White R, Pollak J, Tal M. Pelvic embolization for intractable postpartum hemorrhage: long-term follow-up and implications for fertility. Obstet Gynecol 2003;102(5 Pt 1):904-10.

21. Boulleret C, Chahid T, Gallot D, Mofid R, Tran Hai D, Ravel $A$, et al. Hypogastric arterial selective and superselective embolization for severe postpartum hemorrhage: a retrospective review of 36 cases. Cardiovasc Intervent Radiol 2004;27:344-8.

22. Vegas G, Illescas T, Munoz M, Perez-Pinar A. Selective pelvic arterial embolization in the management of obstetric hemorrhage. Eur J Obstet Gynecol Reprod Biol 2006;127:68-72.

23. Kim YJ, Yoon CJ, Seong NJ, Kang SG, An SW, Kim YS, et al. Failed pelvic arterial embolization for postpartum hemorrhage: clinical outcomes and predictive factors. J Vasc Interv Radiol 2013;24:703-9.

24. Deux JF, Bazot M, Le Blanche AF, Tassart M, Khalil A, Berkane $\mathrm{N}$, et al. Is selective embolization of uterine arteries a safe alternative to hysterectomy in patients with postpartum hemorrhage? AJR Am J Roentgenol 2001;177:145-9.

25. Hunter LA. Exploring the role of uterine artery embolization in the management of postpartum hemorrhage. J Perinat Neonatal Nurs 2010;24:207-14.

26. Sentilhes L, Gromez A, Clavier E, Resch B, Verspyck E, Marpeau L. Predictors of failed pelvic arterial embolization for severe postpartum hemorrhage. Obstet Gynecol 2009;113:992-9.

27. Poujade O, Zappa M, Letendre I, Ceccaldi PF, Vilgrain V, Luton D. Predictive factors for failure of pelvic arterial embolization for postpartum hemorrhage. Int J Gynaecol Obstet 2012;117:119-23.

28. Soncini E, Pelicelli A, Larini P, Marcato C, Monaco D, Grignaffini $A$. Uterine artery embolization in the treatment and prevention of postpartum hemorrhage. Int J Gynaecol Obstet 2007;96:181-5.

29. Salazar GM, Petrozza JC, Walker TG. Transcatheter endovascular techniques for management of obstetrical and gynecologic emergencies. Tech Vasc Interv Radiol 2009;12:139-47.

30. Lee JS, Shepherd SM. Endovascular treatment of postpartum hemorrhage. Clin Obstet Gynecol 2010;53:20918. 